\title{
BLOQUEIOS PERINEURAIS DIAGNÓSTICOS EM EQUINOS: REVISÃO DE PONTOS RELEVANTES E A CONTRIBUIÇÃO DA ULTRASSONOGRAFIA
}

\author{
Beatriz Tofani Maia ${ }^{1}$ \\ Caroline Jubran Pascual ${ }^{2}$ \\ Anderson Fernando de Souza ${ }^{3}$ \\ Cynthia do Prado Vendruscolo ${ }^{4}$ \\ Raquel Yvonne Arantes Baccarin ${ }^{5}$ \\ André Luis do Valle De Zoppa ${ }^{5}$
}

\begin{abstract}
RESUMO
As injeções anestésicas perineurais são frequentemente utilizadas para auxiliarem na identificação dos locais potencialmente causadores de dor e consequentemente claudicação nos equinos. Nesse sentido, o conhecimento anatômico detalhado das estruturas neurais é importante para realização correta e eficiente dos bloqueios perineurais nos membros locomotores de equinos, não gerando dúvidas em suas interpretações. Para tanto, a ultrassonografia torna-se uma ferramenta importante no processo de aprendizagem, além de apontar a melhor forma de realizar o procedimento. Esta revisão tem por objetivo apresentar os fatores que interferem na realização das injeções perineurais e como a ultrassonografia pode ser útil no processo de aprendizagem pode auxiliar na execução destes procedimentos.
\end{abstract}

Palavras-chave: Injeções perineurais, estruturas anatômicas, exame de ultrassom.

\begin{abstract}
Perineural anesthetic injections are often used to assist in the identification of potentially painful sites and, consequently, lameness in horses. In this sense, detailed anatomical knowledge of neural structures is important for the correct and efficient performance of perineural blocks in the limbs of horses, generating no doubts in their interpretations. For this, ultrasonography becomes an important tool in the learning process, in addition to pointing out the best way to perform the procedure. This review aims to present the factors that interfere with the performance of perineural injections and how ultrasound can be useful in the learning process can assist in the execution of these procedures.
\end{abstract}

Keywords: Perineural injections, anatomical structures, ultrasound.

\section{RESUMEN}

Las inyecciones de anestesia perineural a menudo se usan para ayudar en la identificación de sitios potencialmente dolorosos y, en consecuencia, la cojera en los caballos. En este sentido, el conocimiento anatómico detallado de las estructuras neurales es importante para el funcionamiento correcto y eficiente de los bloqueos perineurales en las extremidades locomotoras de los caballos, sin generar dudas en sus interpretaciones. Para esto, la ecografía se convierte en una herramienta importante en el proceso de aprendizaje, además de señalar la

\footnotetext{
${ }^{1}$ Universidade Anhembi Morumbi. Correspondência: beatriztofani@gmail.com

2 caroljpascual@usp.br

${ }^{3}$ Posgraduado em Clínica Cirúrgica Veterinária Faculdade de Medicina Veterinária e Zootecnia, Universidade de São Paulo, São Paulo, SP. anderson.sji@hotmail.com

${ }^{4}$ Posgraduado em Clínica Veterinária, Universidade de São Paulo, São Paulo, SP. cynthiaimpoluto@hotmail.com

${ }^{5}$ Docente da Faculdade de Medicina Veterinária e Zootecnia, Universidade de São Paulo, São Paulo, SP, baccarin@usp.br
}

Maia BT, Pascual CJ, Souza AF, Vendruscolo CP, Baccarin RYA, Zoppa ALV. Bloqueios perineurais diagnósticos em equinos: Revisão de pontos relevantes e a contribuição da ultrassonografia. Vet. e Zootec. 2020 dez; 27: 001-010. 
mejor manera de realizar el procedimiento. Esta revisión tiene como objetivo presentar los factores que interfieren con el rendimiento de las inyecciones perineurales y cómo la ecografía puede ser útil en el proceso de aprendizaje puede ayudar en la ejecución de estos procedimientos.

Palabras-clave: Inyecciones perineurales, estructuras anatómicas, guiadas por ultrasonido.

\section{INTRODUÇÃO}

Os equinos são acometidos por lesões musculoesqueléticas agudas ou crônicas resultando em claudicação, que por sua vez diminuem o uso funcional e causam enormes perdas econômicas, ao gerar gastos para diagnóstico e tratamento. Na tentativa de auxiliar o estabelecimento dos diagnósticos relacionados às afecções do sistema locomotor, ou mesmo aliviar as dores causadas por elas, a utilização de diferentes soluções anestésicas em injeções perineurais têm se mostrado muito úteis (1).

A analgesia diagnóstica é aplicada para auxiliar na localização da(s) causa(s) de claudicação e continua sendo o único método eficaz para determinar o local da dor. As diferentes técnicas consistem em injeção intrassinovial, infiltração subcutânea de anestésico local sobre uma estrutura dolorosa e injeção perineural regional (2). Embora necessitem de despesas mínimas de equipamentos e materiais, essas técnicas exigem conhecimento apurado da anatomia, habilidades técnicas e experiência clínica (3). A ausência parcial ou total dessas características gera erros na interpretação dos resultados da analgesia diagnóstica, que por vezes não são identificados, levando à definição de diagnósticos nebulosos (2).

Por meio do exame ultrassonográfico é possível compreender melhor a composição anatômica e gerar informações mais acuradas em relação ao melhor local para realização do bloqueio anestésico.

Antes do uso da ultrassonografia no auxílio de injeções perineurais, a eficiência do procedimento era difícil de ser determinada, ou seja, a correta posição da ponta da agulha em relação aos nervos e como o fármaco era distribuído dependiam do conhecimento anatômico de dissecações e de desenhos de livros, o que apresenta divergências dos tecidos vivos (4).

A aparência ultrassonográfica e do tamanho dos nervos ciático, tibial, peroneal, supra escapular, radial e ulnar (5) e o nervo mediano (6) foi descrito, bem como comparação com o tamanho anatômico e a localização desses nervos no equino adulto normal. Denoix et al. (2018) descreveram a anatomia ultrassonográfica do aspecto caudomedial do compartimento crural caudal superficial que contêm o nervo tibial, além de apresentarem a técnica para realizar a injeção guiada por ultrassonografia desse nervo.

Esta revisão tem por objetivo apresentar os fatores que interferem na realização das injeções perineurais e como a ultrassonografia pode ser útil no processo de aprendizagem pode auxiliar na execução destes procedimentos.

\section{Utilização dos Bloqueios Anestésicos}

O aparelho locomotor dos equinos recebe notoriedade por representar um sistema de sustentação e da dinâmica locomotora. Suas competências classificam a espécie de forma extraordinária para utilização em diferentes modalidades, como montaria e trabalho, e nos dias de hoje principalmente para fins desportivos. Os membros locomotores da espécie equina atuam como um sistema de alavancas com configuração geométrica, que afetam diretamente a carga nos ossos e tecidos moles (7). Comumente, o afastamento dos equinos de suas atividades está associado às lesões do aparelho locomotor, seguido por enfermidades digestórias e respiratórias (8).

Maia BT, Pascual CJ, Souza AF, Vendruscolo CP, Baccarin RYA, Zoppa ALV. Bloqueios perineurais diagnósticos em equinos: Revisão de pontos relevantes e a contribuição da ultrassonografia. Vet. e Zootec. 2020 dez; 27: 001-010. 
O emprego de bloqueios anestésicos como meio auxiliar no diagnóstico de claudicação em equinos é muito utilizado no exercício da Medicina Veterinária, sendo conveniente nos casos em que, mesmo após anamnese apropriada e detalhado exame físico do aparelho locomotor, a origem e a região específica desta claudicação ainda não foram reconhecidas (8). A expectativa após a realização desses bloqueios é que o animal deixará ou diminuirá o grau de claudicação, voltando a colocar carga e utilizar temporariamente o membro acometido, enquanto a área que contém a lesão estiver dessensibilizada (9). Faz-se necessário bom conhecimento anatômico das regiões abordadas, sendo imprescindível a atualização constante, uma vez que novos estudos avaliando sensibilidade e especificidade em relação a novos acessos para a aplicação da técnica estão sempre sendo realizados. Sem o conhecimento das regiões assistidas por cada nervo periférico, bem como da possibilidade de difusão de solução anestésica para estruturas adjacentes, torna-se difícil interpretar os resultados, e diagnósticos equivocados podem ser produzidos. O bom conhecimento anatômico também é fundamental quando a abordagem é feita com finalidades terapêuticas utilizando-se anestésicos de longa duração ou neurolíticos $(3,10)$.

\section{Farmacologia dos Anestésicos Locais}

Os nervos periféricos transmitem estímulos nociceptivos de um local determinado para a medula espinhal principalmente por meio de fibras finas $A \delta$ mielinizadas e fibras $C$ não mielinizadas. Quando ocorre a despolarização, há um súbito influxo de íons de sódio pelos canais de sódio dependentes de voltagem. Isso se propaga ao longo do nervo como um potencial de ação até a sinapse com os interneurônios da medula espinhal. Os anestésicos locais exercem seu efeito reversível bloqueando os canais de sódio dependentes de voltagem e estabilizando a membrana do nervo $(11,12)$. Os anestésicos locais são bases fracas e para que exerçam seu efeito devem se dissociar em meio alcalino (13). Em tecidos infectados, inflamados ou isquêmicos a qualidade da anestesia local é baixa, pois o meio relativamente ácido nestes tecidos inibe a dissociação do fármaco (14).

Em comparação com a maioria dos anestésicos locais, a mepivacaína e a lidocaína são considerados de ação rápida e têm duração de ação relatada de aproximadamente uma hora e duas horas, respectivamente. Em contraste, a bupivacaína apresenta um início intermediário, mas tem duração de ação muito mais longa (3 a 6 horas), a ropivacaína (duração de 3 à 5 horas) também é bastante utilizada em concentração de $0,5 \%$ para bloqueios contínuos porque produz menor bloqueio motor (14), tornando-se mais adequada para fornecer analgesia terapêutica do que diagnóstica. Os efeitos colaterais sistêmicos das técnicas analgésicas diagnósticas são raros. Sinais cardiovasculares ou do sistema nervoso central, incluindo fasciculações, ataxia e colapso podem ocorrer (14). A intoxicação sistêmica exigiria uma dose muito acima da comumente utilizada, mesmo para extensa avaliação diagnóstica.

\section{Neuroanatomia}

Os nervos periféricos são estruturas lineares altamente ordenadas. Eles são compostos de feixes de fibras nervosas ou fascículos. Cada fascículo é um grupo de fibras nervosas individuais embutidas em um estroma frouxo de colágeno e fibroblastos chamado endoneuro. Cada fascículo é envolto em perineuro e todo o nervo é envolvido no epineuro (15) e todo o feixe nervoso é circundado por uma camada de tecido conjuntivo mais frouxo, denominado paraneuro (Figura 1). 


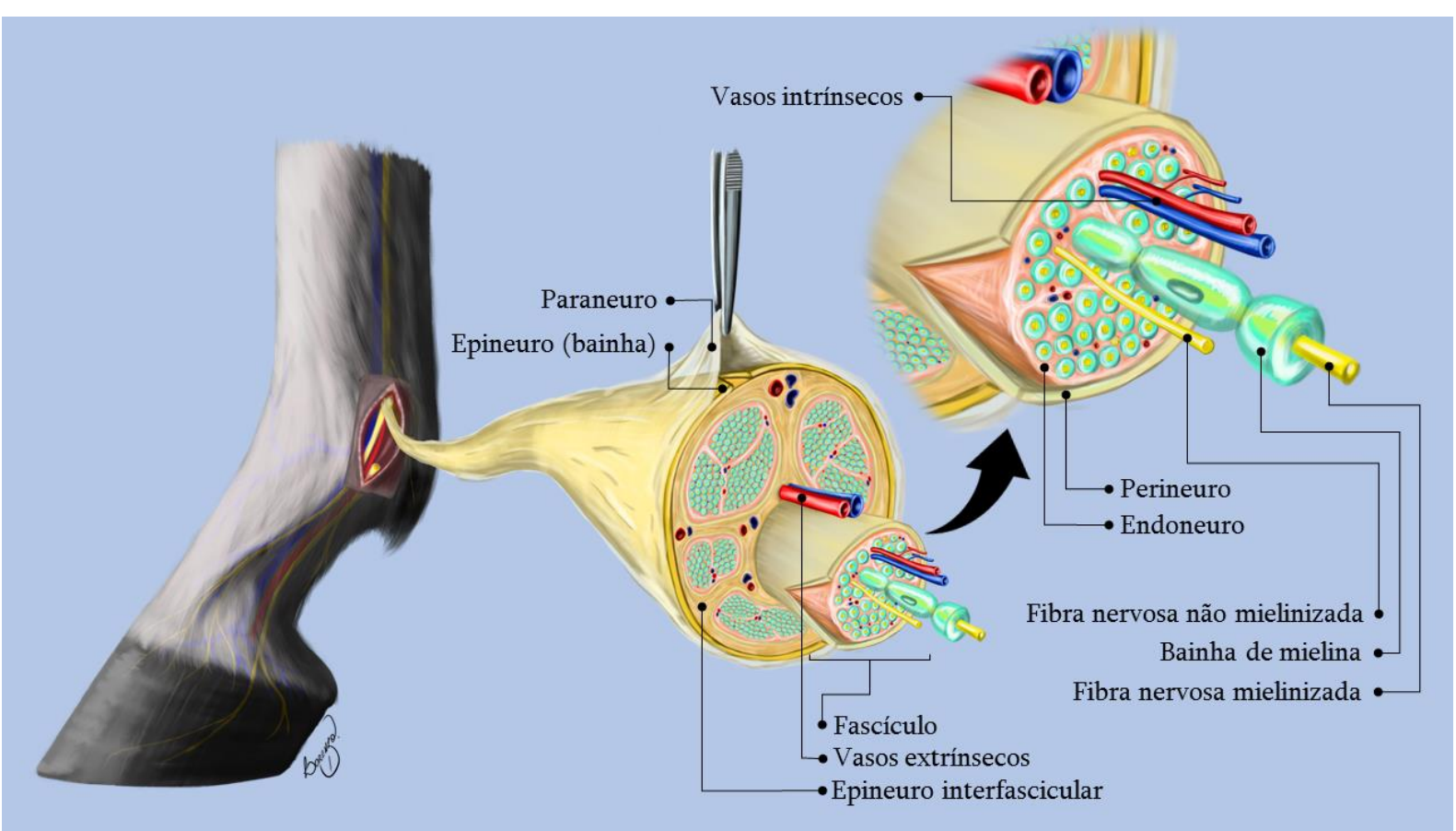

Figura 1. Esquema demostrando os aspectos morfológicos de um nervo periférico em membro equino. Crédito: Lorenzo C. Vicensi.

A inervação para o membro torácico distal se origina no plexo braquial, que por sua vez é oriunda dos três últimos nervos cervicais e dos dois primeiros nervos torácicos (C6-T2). A inervação sensitiva para a porção distal é fornecida pelos nervos mediano e ulnar. O nervo mediano (C8-T2) é o maior ramo do plexo braquial e encontra-se no aspecto caudomedial do rádio. No terço médio do rádio, o nervo mediano se divide no nervo palmar medial e um ramo lateral que se une ao nervo ulnar para formar o nervo palmar lateral. O nervo ulnar, na porção distal do rádio, encontra-se na fáscia entre os músculos flexores ulnar do carpo e ulnar lateral, e ramifica-se em ramos nervosos superficial e profundo, unindo-se este último ao ramo lateral do nervo mediano para formar o nervo palmar lateral. Os nervos palmar lateral e medial cursam distalmente no aspecto abaxial do membro entre o ligamento suspensor (SL) e o tendão flexor digital profundo juntamente com a veia e artéria palmar (medialmente) correspondente $(16,17)$. Os nervos metacarpianos palmares originam-se do ramo profundo do nervo palmar lateral, distal ao osso acessório do carpo na região do metacarpo proximal e penetram profundamente ao nível do ligamento suspensório, passando em torno da sua borda lateral, para finalmente ficar na face axial de cada osso metacarpiano acessório, em que se denominam como nervos metacarpianos palmares, lateral e medial $(17,18)$.

Na região média do metacarpo, o nervo palmar medial emite um ramo comunicante que cruza sobre o tendão flexor digital superficial, onde costuma ser palpável, para em seguida se unir ao nervo palmar lateral (19). Entretanto, no membro pélvico esse ramo é geralmente rudimentar ou inexistente (16), e parece estar localizado mais distalmente do que no membro torácico. Quando os bloqueios do nervo plantar são realizados no membro pélvico, a contribuição do ramo comunicante na retransmissão do estímulo nociceptivo pode ser desconsiderada (2).

O aporte neural para o membro pélvico distal é suprido predominantemente pelo nervo isquiático, que tem origem das raízes neurais de L6 a S2, que subsequentemente se ramifica no nervo tibial maior e no nervo peroneal menor à medida que sai da cavidade pélvica (16). $O$ nervo tibial continua distalmente no aspecto caudal da tíbia, em estreita associação com o ventre muscular do flexor digital superficial e do gastrocnêmio. Na tíbia distal, o nervo tem localização mais superficial dorsomedial ao músculo gastrocnêmio e caudal ao músculo flexor digital 
profundo, localizado entre uma fáscia subcutânea e uma muscular (20). O nervo tibial continua distalmente, ramificando-se nos nervos plantar lateral e medial no nível do tarso. Ambos os nervos passam medialmente ao calcâneo antes de assumirem localização semelhante ao membro torácico na face abaxial do membro entre o ligamento suspensório (LS) e o tendão flexor digital profundo (TFDP) $(16,18)$.

Semelhante ao membro torácico, os nervos metatarsianos plantares são originários do nervo plantar lateral na região proximal do quarto metatarsiano. Aqui, o ramo profundo do nervo plantar lateral passa profundamente ao ligamento suspensório para alinhar-se no aspecto axial dos segundo e quarto metatarsianos, como nervos metatarsianos plantares lateral e medial $(16,17)$.

No nível da articulação femorotibiopatelar, o nervo fibular está localizado caudalmente ao ligamento colateral lateral da articulação fermorotibial e se divide em ramos superficiais e profundos. Ambos os ramos passam distalmente no aspecto dorsolateral da tíbia. Na região distal da tíbia, os nervos estão localizados entre os ventres musculares do extensor digital lateral e o extensor digital longo. O ramo superficial é palpável nesse local e o ramo profundo está próximo a superfície periosteal da tíbia. O ramo profundo passa distalmente em estreita associação com o tendão extensor digital longo e divide-se no tarso dorsal nos nervos metatarsianos dorsais lateral e medial $(16,18)$.

Proximal à articulação metacarpo/metatarsofalangeana, ambos os nervos palmares/plantares se dividem em um ramo dorsal e um nervo digital palmar/plantar. Os ramos dorsais estão inicialmente entre a artéria e veias digitais palmares/plantares (17) e, são responsáveis pela inervação sensorial da pele da região metacarpofalangeana, parte dorsal das articulações metacarpofalangeana, interfalangeanas proximal e distal, cório coronário, partes dorsais dos córios laminar e solear, e parte dorsal da cartilagem alar da falange distal $(17,18)$. Já os nervos digitais palmar/plantar são a continuação direta e, normalmente, dispõem-se em posição palmar/plantar à artéria digital correspondente, para inervarem a derme lamelar dos talões, quartos do casco, derme da sola e ranilha, ligamento ímpar sesamoideo, bursa do navicular, articulação interfalangeana distal, falange distal e os coxins digitais $(17,21,22)$.

\section{Interpretação da Analgesia Diagnóstica}

O perfeito domínio das técnicas permite que as injeções perineurais sejam realizadas com sucesso e segurança, minimizando as chances de complicações secundárias, de se produzir diagnósticos falso-negativos, além de assegurar o sucesso esperado dos tratamentos.

Após a injeção perineural, pode haver redução do grau de claudicação. Muitos clínicos consideram que uma resposta positiva à analgesia regional seria a diminuição de $70 \%$ ou mais na intensidade da claudicação (3) e uma resposta positiva à anestesia intrasinovial seria de $50 \%$ ou mais (2). Caso a resposta seja discreta, ou seja, uma melhora de $50 \%$ ou menos na intensidade de claudicação, pode ser difícil de avaliar. Em estudo comparando avaliações objetivas e subjetivas de equinos claudicantes, a concordância na graduação entre médicos veterinários experientes descrita, de forma subjetiva, foi baixa (23). A avaliação subjetiva também é propensa a viés, pois a expectativa de melhora pode levar o avaliador a acreditar que a claudicação melhorou após analgesia diagnóstica, mesmo sem ter sido feita (24). Atualmente se tornou mais frequente o uso de diferentes dispositivos de detecção de claudicação automatizado que utilizam sensores inerciais sem fio, permitindo medir a assimetria leve e consistente, gerando um número objetivo, e quantificando a melhora exata após a anestesia diagnóstica $(25,26)$.

Maia BT, Pascual CJ, Souza AF, Vendruscolo CP, Baccarin RYA, Zoppa ALV. Bloqueios perineurais diagnósticos em equinos: Revisão de pontos relevantes e a contribuição da ultrassonografia. Vet. e Zootec. 2020 dez; 27: 001-010. 


\section{Ultrassonografia}

O ultrassom é produzido por ondas sonoras com frequências acima de $20.000 \mathrm{~Hz}$, pelo arranjo sequencial de cristais contidos nos transdutores (27). As ondas sonoras são refletidas pelos tecidos e convertidas pelos transdutores em energia elétrica e transformadas em imagens bidimensionais em uma escala de tons de cinza (28). A frequência do ultrassom é inversamente relacionada com o seu comprimento de onda, fazendo variar sua profundidade de penetração nos tecidos (27). Com a elevação da frequência, há maior resolução das imagens, porém a profundidade das estruturas visualizadas é menor; com a redução da frequência, a resolução das imagens diminui, mas a penetração das ondas sonoras aumenta, possibilitando a visualização de estruturas mais profundas.

A velocidade de condução das ondas é específica para cada tecido, as ondas sonoras são propagadas nos tecidos mais ricos em água numa velocidade de $1.540 \mathrm{~m} / \mathrm{s}$, enquanto no ar e ossos trafegam entre 440 e $4.080 \mathrm{~m} / \mathrm{s}$, respectivamente (28). Isto gera diferença na reflexão dessas ondas (ecogenicidade), resultando em contrastes de branco, preto e cinza delimitando as estruturas anatômicas. A impedância acústica dos tecidos é produto de sua densidade pela velocidade de propagação (27). Estruturas hiperecóicas refletem mais as ondas sonoras e são representadas por áreas brancas como ossos, tendões e gordura. Estruturas hipoecóicas são representadas por regiões pretas onde as ondas são atenuadas como nos tecidos ricos em água. A nitidez das imagens geradas é dependente da qualidade do equipamento, do transdutor escolhido, da habilidade do operador para realização e interpretação do exame e dos ajustes realizados no aparelho, que maximizam a resolução das imagens (28).

\section{Ultrassonografia do Nervo Periférico}

Em humanos, a ultrassonografia do nervo periférico tem sido usada para avaliar a aparência normal e anormal, assim como para realização de bloqueios guiados no pré-cirúrgico e colocação de cateteres perineurais para controle de dor (29). O desenvolvimento da ultrassonografia de nervo periférico em cavalos pode ser útil para o diagnóstico de neuropatias (5), bem como para realização de bloqueios anestésicos diagnósticos ou contínuos. O principal requisito para bloqueios anestésicos regionais bem-sucedidos é garantir a difusão ideal do anestésico local em torno das estruturas neurais. Esse objetivo é alcançado com mais eficiência sob visualização ultrassonográfica (4), pois com a visualização do nervo, é possível determinar qual a posição anatômica em que ele se encontra e escolher o tamanho adequado da agulha (6).

Como a maioria dos nervos periféricos geralmente são pequenos e superficiais, quanto maior a frequência do transdutor a ser utilizada é melhor (15). As estruturas neurais podem ser visualizadas em cortes longitudinais ou transversais (28). Os nervos periféricos podem ter formas ovais, triangulares ou redondas e alguns apresentam essas três formas em seu trajeto (30). O rastreamento dos nervos periféricos é dificultado por sua alta mobilidade, sendo mais facilmente realizado no corte transversal. Algumas estruturas como tendões, pequenos vasos e tecido conjuntivo, podem ser confundidas com nervos periféricos (28).

Todos os nervos tanto em cadáveres como em cavalos vivos possuem padrão semelhante no plano longitudinal, dependendo da sua localização: próximo de sua origem na medula espinhal apresentam duas bordas paralelas, retas, nitidamente hiperecóicas, com centro relativamente hipoecóico; perifericamente, os nervos são visualizados de forma que o interior é também hipoecóico, mas com pequenos pontos hiperreflexivos. Ocasionalmente, quando o nervo é mais superficial e pode ser avaliado com mais detalhes, podem ser observados ecos internos lineares (5).

Em corte longitudinal, a imagem do nervo fibular profundo é a mais fácil de ser avaliada, provavelmente devido à sua posição relativamente superficial. Ele apresenta borda circular 
hiperecóica com centro hipoecóico. Os planos de fáscia têm aparência longitudinal semelhante aos nervos, mas a fáscia aparece como uma única linha hiperecóica, e se houver bordas duplas presentes, geralmente não eram paralelas. Os vasos também se assemelham aos nervos, mas suas bordas se ramificam e geralmente não são tão hiperecóicas, o fluxo sanguíneo pode ser visto com auxílio do doppler e powerdoppler, e os vasos também podem ser colabados pressionando o probe sobre eles (Figura 2). Não há diferenças aparentes na ecogenicidade do nervo em relação ao peso, raça ou sexo, havendo apenas diferenças em sua área transversal e profundidade (6). Nervos identificados usando o transdutor linear são geralmente mais fáceis de seguir. Isso ocorre devido à configuração da sonda em relação à natureza linear dos nervos e à maior resolução desse transdutor (5).

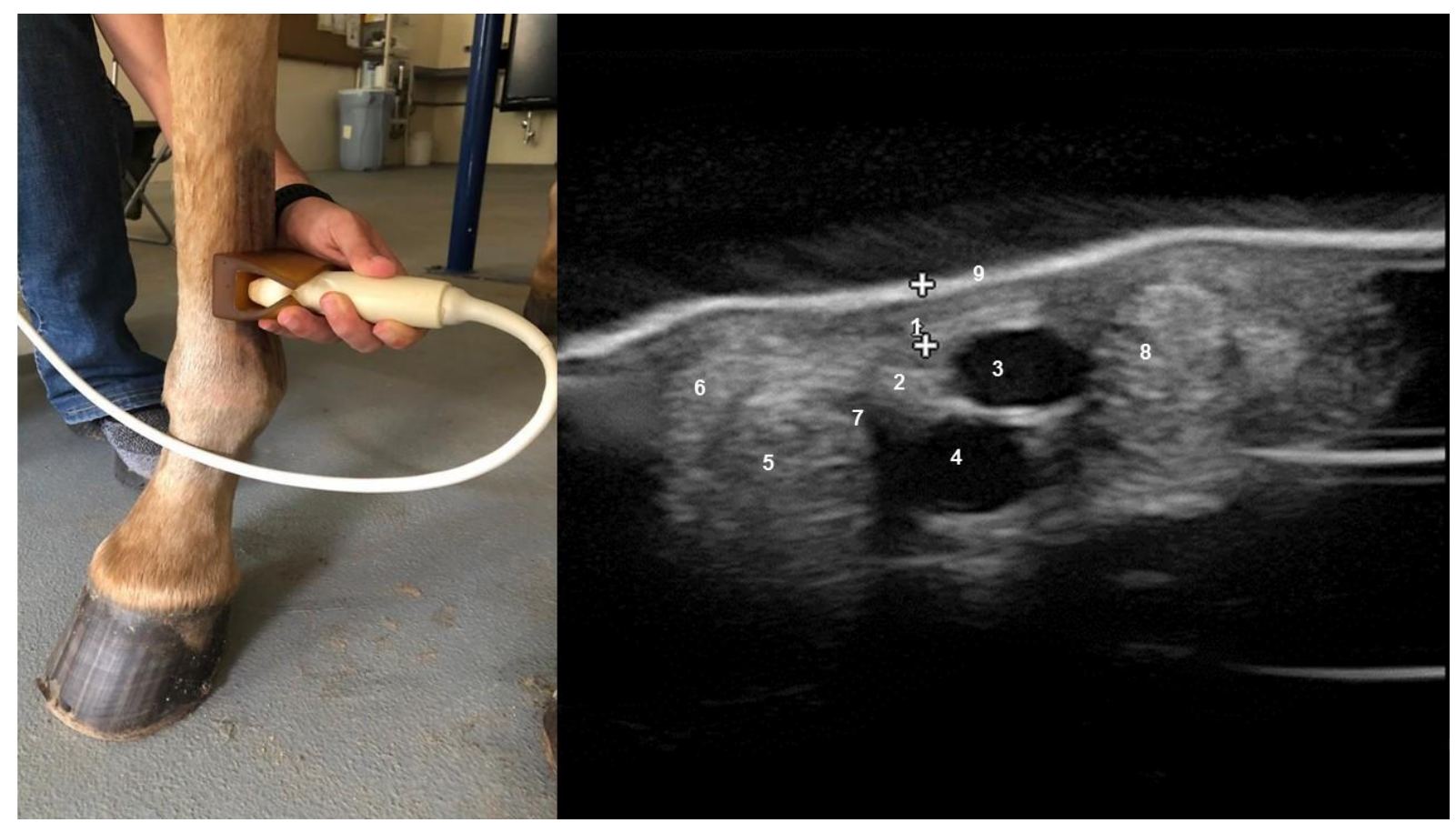

Figura 2. Aspecto ultrassonográfico em corte transversal da face medial do metacarpo esquerdo distalmente a extremidade distal do quarto metacarpiano; dorsal a esquerda, palmar a direita. 1 - distância da pele até superfície abaxial do nervo palmar medial, intervalo entre as duas cruzes ( $3 \mathrm{~mm}), 2$ - nervo palmar medial, 3 - veia digital palmar medial, 4 - artéria digital palmar, 5 - tendão flexor digital profundo, 6 - tendão flexor digital superficial, 7 - bainha digital, 8 - ramo medial do ligamento suspensório, 9 pele.

\section{Realização de Bloqueios Perineurais Guiados por Ultrassom}

O primeiro passo no bloqueio neural guiado por ultrassom é realizar antissepsia da pele e recobrir o probe com luva, previamente preenchida com pequena quantidade de gel, ou proteção adesiva estéril. Posteriormente, o ideal é visualizar todas as estruturas anatômicas na área alvo. Todas as variáveis de ultrassom ajustáveis, ou seja, profundidade de penetração, frequências e posição das zonas focais, devem ser otimizadas para melhor identificação das estruturas anatômicas de interesse (4).

A agulha é identificada como uma estrutura hiperecóica formando sombra acústica, podendo também ser identificada pelo movimento direto da agulha e deslocamento do tecido, havendo agulhas que são mais ou menos sonovisíveis (Figura 3). É importante encher o sistema de agulha com anestésico local antes da punção para evitar a inclusão de ar, que se aplicado formará linha hiperecogenica com sombra acústica ou atenuação de eco, dificultando ou 
impossibilitando o procedimento. Quando a agulha está posicionada de maneira ideal, o anestésico local é administrado sob visualização ultrassonográfica direta até que as estruturas neurais sejam cercadas por anestésico local, formando imagem anecóica na periferia do nervo alvo. Se o anestésico local se espalhar na direção errada, a agulha poderá ser reposicionada em tempo real (4).

A opção de visualizar diretamente a distribuição do anestésico local por ultrassonografia minimiza as doses a serem administradas para o bloqueio efetivo do nervo, o que é particularmente relevante em procedimentos de múltiplos bloqueios (4).

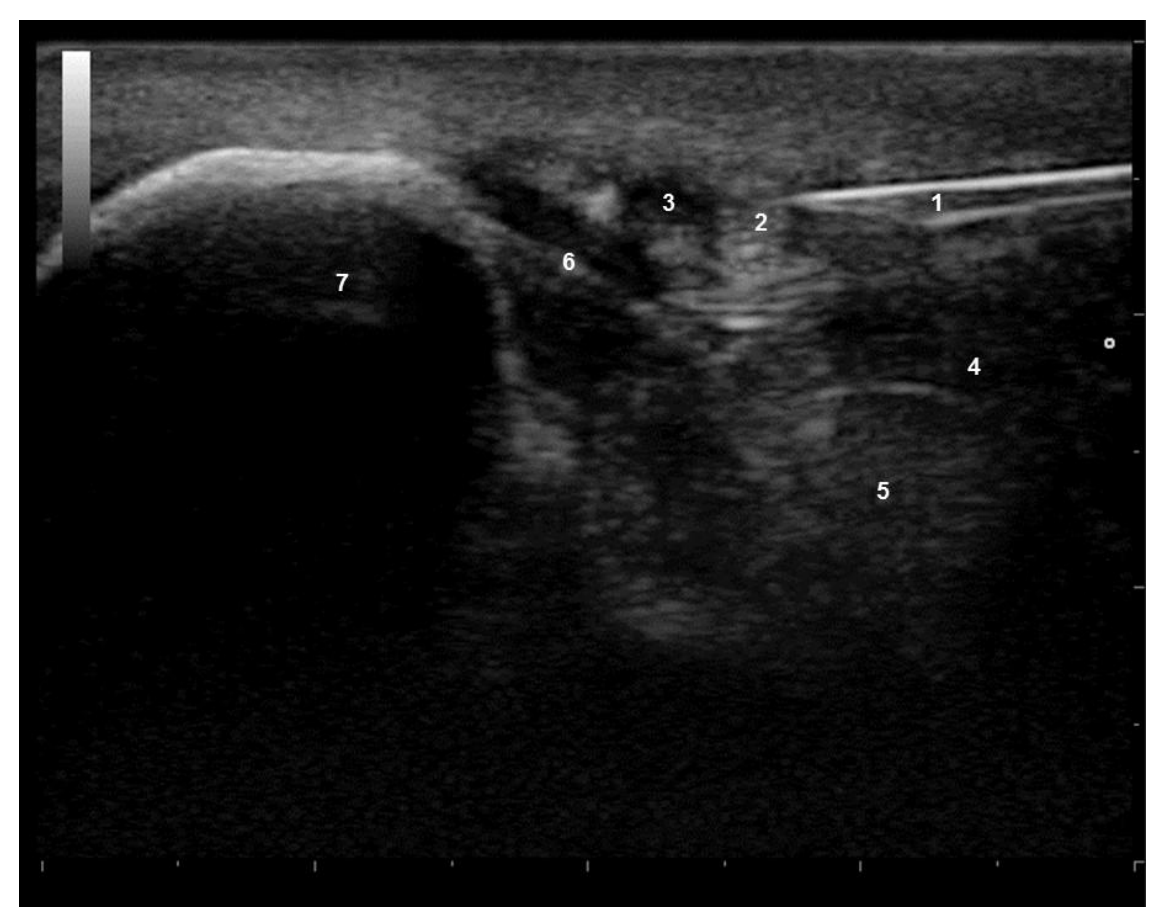

Figura 3. Infiltração perineural guiada por ultrassonografia do nervo digital plantar lateral ao nível da base do osso sesamóide proximal em equino. Corte transversal, com transdutor linear. Dorsal está à esquerda. 1 - agulha, 2 - nervo digital plantar lateral, 3 - artéria digital lateral, 4 - tendão flexor digital superficial, 5 - tendão flexor digital profundo, 6 - ligamento anular e 7 - osso sesamóide proximal lateral.

\section{CONSIDERAÇÕES FINAIS}

Os bloqueios perineurais são muito utilizados na prática clínica, dessa forma, o amplo conhecimento anatômico das estruturas são de extrema importância para os médicos veterinários de equinos, assim como a utilização da ultrassonografia como meio auxiliar para tornar o bloqueio anestésico mais preciso. Nesse sentido, justifica-se a continuidade de estudos sobre variações anatômicas e características ultrassonográficas dos nervos periféricos dos equinos.

\section{REFERÊNCIAS}

1. Luna SPL. Anestesias perineurais e regionais em equinos. Rev Educ Contin CRMV-SP. 1998;1:24-30.

2. Seabaugh K, Selberg K, Valdes-Martinez A. Assessment of the tissue diffusion of anesthetic agent following administration of a low palmar nerve block in horses. J Am Vet Med Assoc. 2011;239:1334-40.

Maia BT, Pascual CJ, Souza AF, Vendruscolo CP, Baccarin RYA, Zoppa ALV. Bloqueios perineurais diagnósticos em equinos: Revisão de pontos relevantes e a contribuição da ultrassonografia. Vet. e Zootec. 2020 dez; 27: 001-010. 
3. Bassage IILH, Ross MW. Diagnostic analgesia. In: Ross MW, Dyson SJ, editors. Diagnosis and management of lameness in the horse. 2nd ed. St. Louis: Saunders Elsevier; 2011. p.10035 .

4. Marhofer P, Greher M, Kapral S. Ultrasound guidance in regional anaesthesia. Br J Anaesth. 2005; 1:7-17.

5. Alexander K, Dobson H. Ultrasonography of peripheral nerves in the normal adult horse. Vet Radiol Ultrasound. 2003;44:456-64.

6. Souto MTM, Fantoni DT, Hamaji A, Hamaji M, Vendruscolo CP, Otsuki DA, et al. Ultrasound-guided continuous block of median and ulnar nerves in horses: development of the technique. Vet Anaesth Analg. 2020;47:405-13.

7. Stover SM. The epidemiology of Thoroughbred racehorse injuries. Clin Tech Equine Pract. $2003 ; 2: 312-22$.

8. Baxter GM, Stashak T. Perineural and intrasynovial anesthesia. In: Baxter GM, editor. Adams' and Stashak's lameness in horses. 6th ed. Philadelphia: Wiley-Blackwell; 2011. p.173-202.

9. Dyson SJ, Kidd L. A comparison of responses to analgesia of the navicular bursa and intraarticular analgesia of the distal interphalangeal joint in 59 horses. Equine Vet J. 1993;25:938.

10. Baccarin RYA, Brossi PM, Silva LCLC. Guia ilustrado para injeção perineural em membros locomotores de equinos. São Paulo: Quiron Comunicação; 2015.

11. Andrade SF, Cassu RN. Analgésicos. In: Andrade SF, editor. Manual de terapêutica veterinária. 3a ed. São Paulo: Roca; 2008. p.97-113.

12. Butterworth JF, Strichartz GR. Molecular mechanisms of local anesthesia: a review. Anesthesiology. 1990;72:711.

13. Fantoni DTF, Cortopassi S.R.G. Terapêutica do sistema nervoso central: anestésicos locais. In: Andrade SF, editor. Manual de terapêutica veterinária. 3a ed. São Paulo: Roca; 2008. p.460-6.

14. Day TK, Skarda RT. The pharmacology of local anesthetics. Vet Clin North Am Equine Pract. 1991;7:489-500.

15. Thain LMF, Downey DB. Sonography of peripheral nerves: technique, anatomy, and pathology. Ultrasound Q. 2002;18:225-45.

16. Dyce KM, Sack WO, Wensing CJG. Tratado de anatomia veterinária. 4a ed. São Paulo: Elsevier; 2010.

17. Getty R. Anatomia dos animais domésticos. 5a ed. Rio de Janeiro: Guanabara Koogan; 1986. vol.1.

Maia BT, Pascual CJ, Souza AF, Vendruscolo CP, Baccarin RYA, Zoppa ALV. Bloqueios perineurais diagnósticos em equinos: Revisão de pontos relevantes e a contribuição da ultrassonografia. Vet. e Zootec. 2020 dez; 27: 001-010. 
18. Kainer RA, Fails AD. Functional anatomy of the equine musculoskeletal system. In: Baxter GM, editor. Adams and Stashak's Lameness in Horses. 6 ed. Philadelphia: WileyBlackwell; 2011. p.3-72.

19. König HE, Liebich H. Anatomia dos animais domésticos: texto e atlas colorido. 6a ed. Rio de Janeiro: Artmed; 2016.

20. Denoix JM, Beaumont A, Bertoni L. Ultrasonographic guided block of the tibial nerve. Equine Vet Educ. 2018;16.

21. Parks A. Form and function of the equine digit. Vet Clin North Am Equine Pract. 2003;19:285-307.

22. Pollitt CC. Clinical anatomy and physiology of the normal equine foot. Equine Vet Educ. 1992;4:219-24.

23. Keegan K, Dent E, Wilson D, Janicek J, Kramer J, Lacarruba A, et al. Repeatability of subjective evaluation of lameness in horses. Equine Vet J. 2010;42:92-7.

24. Arkell M, Archer R, Guitian R, May SA. Evidence of bias affecting the interpretation of the results of local anesthetic nerve blocks when assessing lameness in horses. Vet Rec. 2006;159:346-9.

25. Pfau T, Boultbee H, Davis H, Walker A, Rhodin M. Agreement between two inertial sensor gait analysis systems for lameness examinations in horses. Equine Vet Educ. 2016;28:2038 .

26. Mccraken M, Kramer J, Keegan J, Lopes M, Wilson DA, Reed SK, et al. Comparison of an inertial sensor system of lameness quantification with subjective lameness evaluation. Equine Vet J. 2012;44:652-6.

27. Kossoff G. Basic physics and imaging characteristics of ultrasound. World J Surg. 2000;24:134-42.

28. Helayel PE, Conceição DB, Oliveira Filho GR. Bloqueios nervosos guiados por ultra-som. Rev Bras Anestesiol. 2007;57:106-23.

29. Fornage BD. Peripheral nerves of the extremities: imaging with US. Radiology. 1988;167:179-84.

30. Sinha A, Chan VWS. Ultrasound imaging for popliteal sciatic nerve block. Reg Anesth Pain Med. 2004;29:130-4.

Recebido em: 30/07/2020

Aceito em: 04/12/2020

Maia BT, Pascual CJ, Souza AF, Vendruscolo CP, Baccarin RYA, Zoppa ALV. Bloqueios perineurais diagnósticos em equinos: Revisão de pontos relevantes e a contribuição da ultrassonografia. Vet. e Zootec. 2020 dez; 27: 001-010. 